\title{
An Investigation into Potentially Lethal Acts of Male-Perpetrated Intimate Partner Violence
}

\author{
Marika Guggisberg \\ The University of Western Australia, Perth, Australia. \\ Email: marika.guggisberg@uwa.edu.au \\ Received September $7^{\text {th }}, 2012$; revised October $5^{\text {th }}, 2012$; accepted October $15^{\text {th }}, 2012$
}

\begin{abstract}
Interest in risk assessment in contemporary discussions of criminal justice issues including the treatment of intimate partner violence is ongoing as scholarship has identified lack of empirical knowledge in this area. The purpose of this paper is to add to current knowledge by reporting on Australian research findings on a number of risk factors associated with fear of homicide in intimate partnerships. Quantitative research methods were used to analyse demographic data on 227 Western Australian women, residing in metropolitan Perth, who had been exposed to potentially lethal forms of male-perpetrated intimate partner violence in the six months prior to participating in the study. Results suggested that certain victim characteristics such as the experience of sexual violence, minority status, being separated, and having a prior history of victimisation appear to be important risk indicators for intimate partner homicide.
\end{abstract}

Keywords: Aboriginal; Fear; Homicide; Intimate; Partner; Minority; Risk Factors; Sexual; Violence; Women

\section{Introduction}

Male-perpetrated intimate partner violence (MP-IPV) remains a serious social problem despite decades of preventative measures and interventions globally [1]. At its most severe, the outcomes of MP-IPV result not only in significant injury but mortality, albeit homicide is generally a rare event. While women also commit murder, they are much more likely to be victims of intimate homicide. The US Bureau of Justice Statistics noted: "Female murder victims are substantially more likely than male murder victims to have been killed by an intimate partner [2]". Up to 80 intimate partner homicides occurred annually in Australia between the late 1980s to the mid-2000s [3]. It was reported that "between 1989 and 1998, 57 percent of female deaths caused by violence were perpetrated by an intimate partner [4]", and evidence from 2006-2007, confirms that "rates of intimate-partner homicide remained constant [5]".

Studies examining intimate partner relationships that end in homicide found differences between homicides involving intimate partners and homicides involving strangers [6].

In keeping with this finding, Decker explained, “... the greater frequency of interaction and attachment to others with whom one is intimately involved creates situations that are likely to lead to disputes, and potentially to fatal violence [7]”.

Campbell and colleagues argued that a history of MP-
IPV victimisation remains one of the strongest risk factors of homicide for women [8]. Similarly, Dobash and Dobash, asserted that "repeat violence against a woman partner has consistently been shown to be a reliable marker of further non-lethal and lethal violence [9]”. Consequently, there appears to be a demand for greater knowledge of specific risk "that might help predict where there is risk of further and more serious violence, including the possibility of homicide [3]”.

\subsection{Predictors of Increased Risk of Homicide}

\subsubsection{Threats-Specific Behaviours}

International research has identified risk factors for potentially lethal outcomes (homicide) of MP-IPV as including a history of violence against a woman partner [10], threats with a weapon, threats to kill the woman and/or the child(ren) [11], attempt to choke/strangle the woman [12], and relationship status [13].

Another important predictor of increased risk of homicides involving intimate partners is sexual violence victimisation [14]. To clarify, the role of sexual violence in intimate relationships requires specific attention as it is not only almost exclusively perpetrated by men, but the violence has been found to be purposefully used to exercise power and dominate the victimised woman [15]. In this regard it is important to note that physical and sexual violence along with no-physical forms of MP-IPV (e.g. controlling behaviours) frequently overlap [16] and occur 
repeatedly rather than as isolated instances [17].

Victimised women reported burning and attempted drowning [11] or strangulation [12] as outcomes of MPIPV. In fact, strangulation was identified in $45 \%$ of attempted homicides and in $43 \%$ of homicides [18].

\subsubsection{Socio-Demographic Characteristics}

Specific socio-demographic characteristics seem to be associated with increased risk of intimate partner homicide. Two key factors have been identified as 1) minority status [8] and 2) relationship status [13].

Minority status has been found to be a risk factor for intimate partner homicide. In an article outlining the disproportionate experience of victimisation of Aboriginal and Torres Strait Islander (ATSI) women in Australia, Stubbs and Tolmie noted that "data consistently demonstrate extreme levels of family violence experienced by Indigenous women and children [19]". These women are up to 35 times more likely than non-ATSI women to sustain injuries requiring hospitalisation from IPV victimisation [20]. Furthermore, intimate partner homicide rates of ATSI Australians are nearly double the proportion of non-ATSI homicides despite them making up less than three percent of the Australian population [19]. It is not surprising then, that Campbell and associates' metaanalysis on intimate partner homicide found that minority status was a statistically significant risk factor [8].

Being married has been found to be a protective factor for MP-IPV victimisation [21].

However, women attempting to leave an abusive and/ or violent intimate partner, seem in greater risk of victimisation and even homicide. Leaving the violent relationship seems often unfeasible for the victimised women. Putt contended that "Leaving is not simple-Many women had left or tried to leave or asked the partner to leave, but leaving can increase the risk of violence and risk of death [3]". Similarly, Block reported that $51 \%$ of women victims in Chicago "were killed as they were trying to leave" and that "leaving was an immediate precipitating factor of the homicide [22]". Dobash and Dobash stated the elevated risk of women who attempt to separate or are separated from an abusive partner stems from issues including possessiveness, jealousy and sometimes custody conflicts [9].

\section{Present Study}

This analysis examined some of the risk factors for intimate partner homicide identified in the literature: sexual violence victimisation, threats with a weapon, threats to kill the woman, prior attempts to choke/strangle the woman, as well as socio-demographic characteristics by women victims who experience increased risk of intimate homicide. It was hypothesised that participants with more extensive IPV victimisation (experiencing sexual vio- lence in addition to other forms of MP-IPV) are more likely than other participants to be subjected to physical violence identified as predictive of high risk of potential homicide (e.g. attempts of choking/strangulation, previous threats of homicide). Given the exploratory nature of this study there were no hypotheses about other correlates that might influence risk of homicide.

The sample of 227 adult women was drawn from a self-selected non-representative community group after ethics approval from the universities and participating agencies were obtained. Study participants were provided with a research pack containing a cover letter, an information statement, which described the study and a survey questionnaire, asking about their experiences of MP-IPV and other related issues, which are not reported here. The research tool was constructed utilising pre-existing subscales, which all returned sound reliability and validity.

Demographic questions were derived from the Australian Bureau of Statistics Census questionnaire, and measures for MP-IPV victimisation reported here utilized items from the Violence Assessment Index [23]. Information from the following items are reported here: "Threatened to kill me"; "Tried to strangle, burn or drown me"; "Used an object to hurt me"; "Threatened to hurt children"; and "Threatened me with an object or weapon".

Answers were provided anonymously and no identifying data were obtained. The questionnaires contained a list of community resources for participants to detach before placing the completed questionnaire into a locked box at participating agencies. Participants were treated in accordance with national guidelines on ethical conduct in human research.

Data were analysed using SPSS version 17. Descriptive statistics, cross-tabulations and odds ratios were used to explore the data. Women experiencing different forms of overlapping violence were placed into groups representing different comparison groups. Group 1 consisted of women who had experienced sexual violence in addition to physical violence and controlling behaviour within the past six months (e.g. was choked, forced to have sex and also restricted in her social life); Group 2 consisted of women who had experienced no sexual violence but were subjected to physical violence and controlling behaviour, (e.g. was threatened to be killed and deliberately kept short of money). $p$-values less than 0.05 were considered statistically significant.

\section{Results}

Of the 235 completed and returned questionnaires, eight (3\%) had to be excluded due to ineligibility (one woman was 17 years of age) or greater than $20 \%$ missing data. A total of 227 questionnaires were included in the final analysis. Of all valid questionnaires, $65 \%$ were obtained from 
a non-government women's health service and 35\% were from a government support service.

Participants were aged between 19 and 65 years $(M=$ 37.4, SD \pm 11.5 years). Ten Aboriginal women (4.4\%) participated in the study, none of the women identified as Torres Strait Islander. The majority of participants were married (53.3\%), followed by those in a dating relationship (19.4\%), separated (15.9\%), or cohabiting (10.6\%) at the time of completing the survey. The majority of women in this sample (92.9\%) had received at least 10 years of formal schooling and $74.0 \%$ currently participated in the workforce.

As seen in Figure 1, 64 women (28.2\%) experienced sexual violence (defined here as either being forced to have sex or sex on demand). Controlling behaviour was the most prevalent form of IPV with 156 (68.7\%) of women reporting this non-physical form of IPV in the past six months. Of these 156 women 122 (78\%) also reported the occurrence of physical and/or sexual violence in the same time frame.

\subsection{Aboriginal Status and MP-IPV}

To assess the influence of Aboriginal status, Chi-square statistics $(p=0.05)$ and risk estimates were calculated (95\% CI). Nine of the ten Aboriginal women in this study experienced sexual violence. Differences in the type of victimisation experienced by Aboriginal women compared to non-Aboriginal women (shown in Table 1) were observed. Non-Aboriginal women tended to be less likely to experience sexual violence when compared to Aboriginal participants.

Seven out of 10 (70\%) Aboriginal women reported a potentially lethal act of violence in the last six months compared to 28 (13\%) of non-Aboriginal women. Expressed as an odds ratio, Aboriginal women were 15.75
(95\% CI = 3.8 - 64.5) times more likely to report any potentially lethal act of violence compared to non-Aboriginal women. When specific potentially lethal acts of violence were examined, the odds of an Aboriginal woman reporting "threats to kill me" (OR $=21.8$; $\mathrm{CI}=5.2$ 90.6); "tried to strangle, burn or drown me" (OR = 12.5; $\mathrm{CI}=3.1$ - 50.8); "used an object to hurt me" (OR = 18.8; $\mathrm{CI}=4.8$ - 73.7); "threatened to hurt children" (OR = 15.4; $\mathrm{CI}=3.7$ - 64.4) or "threaten me with an object or weapon” (OR = 22.9; CI = 5.5 - 95.9) were between 12 and 23 times higher than that for non-Aboriginal women. These risk estimates suggest that the relative odds of Aboriginal women reporting potentially lethal violence by their intimate partner are significantly higher than for non-Aboriginal women.

It is noteworthy that in the six month period prior to entry into the study approximately one in four non-Aboriginal women (25.8\%) experienced sexual violence (i.e. forced sex or sex on demand) by their intimate partner whereas eight of the ten Aboriginal women in this study (80\%) reported sexual violence. Of these, less than $13 \%$ of non-Aboriginal women experienced rape (forced intercourse) whereas five of the 10 Aboriginal women reported having been raped at least once, four of which frequently (5 or more times). These results suggest that Aboriginal women in this study were 11 times more likely to experience sexual violence than non-Aboriginal women $(\mathrm{OR}=11.5 ; 95 \% \mathrm{CI}=2.4$ - 55.8).

\subsection{Relationship Status and MP-IPV}

Separated women in this study were nearly eight times more likely to report experiences of sexual violence in addition to physical violence and controlling behaviour in the previous six months when compared to married women $(\mathrm{OR}=7.6$; $\mathrm{CI}=3.1$ - 19.1) (shown in Table 2).

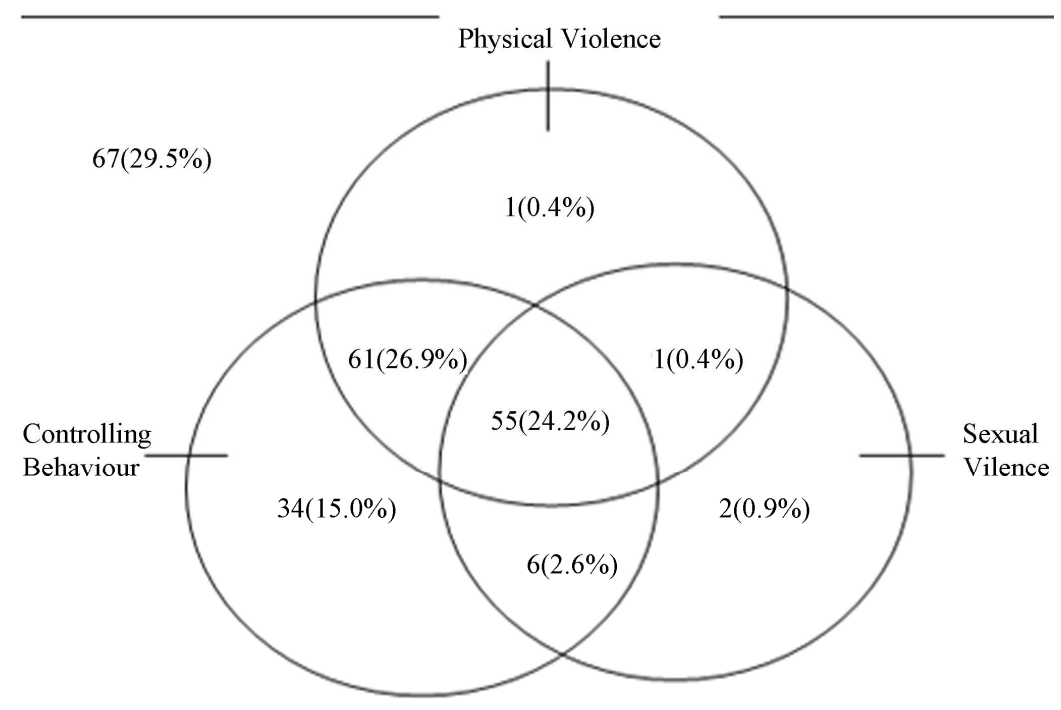

Figure 1. Proportion of different forms of (overlapping) intimate partner violence. 
Table 1. Relative odds of the type of abuse and potentially lethal acts of violence reported in the previous six months by Aboriginal status ( $\mathrm{N}=227)$.

\begin{tabular}{|c|c|c|c|c|c|c|c|}
\hline \multirow[b]{2}{*}{ IPV Victimisation } & \multicolumn{2}{|c|}{$\begin{array}{l}\text { Aboriginal } \\
\mathrm{N}=10\end{array}$} & \multicolumn{2}{|c|}{$\begin{array}{l}\text { Non-Aboriginal } \\
\qquad \mathrm{N}=217\end{array}$} & \multirow[b]{2}{*}{ OR } & \multirow[b]{2}{*}{$95 \% \mathrm{CI}$} & \multirow[b]{2}{*}{$p$-value } \\
\hline & $\mathrm{n}$ & $\%$ & $\mathrm{n}$ & $\%$ & & & \\
\hline Group 1 (sexual, physical violence \& controlling behaviour) & 7 & 70.0 & 48 & 22.1 & 8.2 & $2.1-33.0$ & 0.001 \\
\hline $\begin{array}{c}\text { Group } 2 \text { (physical violence \& controlling behaviour but no } \\
\text { sexual violence) }\end{array}$ & 1 & 10.0 & 60 & 27.6 & 0.3 & $0.4-2.3$ & 0.198 \\
\hline \multicolumn{8}{|l|}{ Specific potentially lethal acts of violence } \\
\hline Threatened to kill me & 7 & 70.0 & 21 & 9.7 & 21.8 & $5.2-90.6$ & $<0.001$ \\
\hline Tried to strangle, burn or drown me & 4 & 40.0 & 11 & 5.1 & 12.5 & $3.1-50.8$ & $<0.001$ \\
\hline Used an object to hurt me & 6 & 60.0 & 16 & 7.4 & 18.8 & $4.8-73.7$ & $<0.001$ \\
\hline Threatened me with an object or weapon & 7 & 70.0 & 20 & 9.2 & 23.0 & $5.5-95.9$ & $<0.001$ \\
\hline
\end{tabular}

OR = odds ratio; $\mathrm{CI}=$ Confidence Interval.

Table 2. Relative odds of the type of abuse reported in the previous six months by relationship status $\left(\mathrm{N}=225^{\wedge}\right)$.

\begin{tabular}{|c|c|c|c|c|c|}
\hline Relationship status versus IPV Victimisation & $\mathrm{n}$ & $\%$ & OR & $95 \% \mathrm{CI}$ & p-value \\
\hline \multicolumn{6}{|l|}{ Group 1 (sexual, physical violence \& controlling behaviour) } \\
\hline Married $(n=121)$ & 17 & 14.0 & Ref $^{*}$ & - & - \\
\hline Dating $(n=44)$ & 11 & 25.0 & 2.0 & $0.8-5.1$ & 0.105 \\
\hline Cohabitating $(\mathrm{n}=24)$ & 6 & 25.0 & 2.0 & $0.6-6.4$ & 0.219 \\
\hline Separated $(\mathrm{n}=36)$ & 20 & 55.6 & 7.6 & $3.1-19.1$ & $<0.001$ \\
\hline \multicolumn{6}{|c|}{ Group 2 (physical violence \& controlling behaviour but no sexual violence) } \\
\hline Married $(\mathrm{n}=121)$ & 31 & 25.6 & $\operatorname{Ref}^{*}$ & - & - \\
\hline Dating $(n=44)$ & 11 & 25.0 & 1.0 & $0.4-2.3$ & 1.000 \\
\hline Cohabitating $(n=24)$ & 13 & 54.2 & 3.4 & $1.3-9.4$ & 0.008 \\
\hline Separated $(n=36)$ & 6 & 16.7 & 0.6 & $0.2-1.6$ & 0.371 \\
\hline
\end{tabular}

${ }^{\wedge}$ Two participants who did not provide information on their relationship status were excluded from analysis; OR = odds ratio; CI = Confidence Interval; *Married women were the reference group against whom the other groups were compared.

There was no difference between women in dating or cohabitating relationships and married women in terms of reporting. However, no significant differences were found in the likelihood of reporting MP-IPV between married, dating and separated women when no sexual violence was involved.

Half of all separated women (18/36) reported at least one potentially lethal act of violence in the previous six months (OR = 7.4; CI = 2.9 - 19.1) (shown in Table 3). Risk estimates suggested that relative to the married women in the study, separated women were found to be more than seven times more likely to report a potentially lethal act of violence in the previous six months. There was no statistically significant difference observed between the number of reported potentially lethal acts of violence between married, dating and cohabitating women. When specific acts of potentially lethal violence were considered, it was observed that separated women had high increased odds of reporting "threatened" acts of violence compared to married women: "threatened to kill me $(\mathrm{OR}=16.6$; CI = 4.9 - 63.0)" and "threatened to hurt children (OR = 11.2; CI = 2.4 - 68.5)”. No statistically significant differences were observed in the specific reported acts of potentially lethal violence for dating and cohabitating women compared to married women in this study.

\section{Discussion}

This analysis confirmed that specific experiences of MP- 
Table 3. Relative odds of potentially lethal acts of violence reported in the previous six months by relationship status $(\mathrm{n}=$ $\left.225^{\wedge}\right)$.

\begin{tabular}{|c|c|c|c|c|c|}
\hline Relationship status versus acts of potentially lethal violence & $\mathrm{n}$ & $\%$ & OR & $95 \%$ CI & $p$-value \\
\hline \multicolumn{6}{|l|}{ At least one potentially lethal act of violence } \\
\hline Married $(n=121)$ & 17 & 14.1 & $\operatorname{Ref}^{*}$ & - & - \\
\hline Dating $(\mathrm{n}=44)$ & 5 & 11.4 & 1.0 & $0.3-3.1$ & 1.000 \\
\hline Cohabitating $(n=24)$ & 6 & 25.0 & 2.5 & $0.7-8.2$ & 0.104 \\
\hline Separated $(n=36)$ & 18 & 50.0 & 7.4 & $2.9-19.1$ & $<0.001$ \\
\hline \multicolumn{6}{|l|}{ Specific Potentially Lethal Acts of Violence } \\
\hline \multicolumn{6}{|l|}{ Threatened to kill me } \\
\hline Married $(n=121)$ & 5 & 4.1 & $\operatorname{Ref}^{*}$ & - & - \\
\hline Dating $(n=44)$ & 3 & 6.8 & 1.7 & $0.3-9.1$ & 0.441 \\
\hline Cohabitating $(\mathrm{n}=24)$ & 3 & 12.5 & 3.3 & $0.5-18.3$ & 0.127 \\
\hline Separated $(n=36)$ & 15 & 41.7 & 16.6 & $4.9-63.0$ & $<0.001$ \\
\hline \multicolumn{6}{|l|}{ Tried to strangle, burn or drown me } \\
\hline Married $(n=121)$ & 4 & 3.3 & $\operatorname{Ref}^{*}$ & - & - \\
\hline Dating $(n=44)$ & 2 & 4.5 & 1.4 & $0.1-10.1$ & 0.659 \\
\hline Cohabitating $(n=24)$ & 2 & 8.3 & 2.7 & $0.2-19.7$ & 0.259 \\
\hline Separated $(\mathrm{n}=36)$ & 6 & 16.7 & 5.9 & $1.3-29.6$ & 0.010 \\
\hline \multicolumn{6}{|l|}{ Used an object to hurt me } \\
\hline Married $(n=121)$ & 5 & 4.1 & Ref $^{*}$ & - & - \\
\hline Dating $(n=44)$ & 3 & 6.8 & 1.7 & $0.3-9.1$ & 0.441 \\
\hline Cohabitating $(n=24)$ & 2 & 8.3 & 2.1 & $0.2-13.8$ & 0.327 \\
\hline Separated $(n=36)$ & 3 & 8.3 & 2.1 & $0.3-11.4$ & 0.385 \\
\hline \multicolumn{6}{|l|}{ Threatened to hurt children } \\
\hline Married $(n=121)$ & 3 & 2.5 & $\operatorname{Ref}^{*}$ & - & - \\
\hline Dating $(n=44)$ & 1 & 2.3 & 0.9 & $0.1-11.7$ & 1.000 \\
\hline Cohabitating $(n=24)$ & 1 & 4.2 & 1.7 & $0.1-22.3$ & 0.519 \\
\hline Separated $(\mathrm{n}=36)$ & 8 & 22.2 & 11.2 & $2.4-68.5$ & $<0.001$ \\
\hline \multicolumn{6}{|l|}{ Threatened me with an object or weapon } \\
\hline Married $(n=121)$ & 6 & 5.0 & Ref $^{*}$ & - & - \\
\hline Dating $(\mathrm{n}=44)$ & 3 & 6.8 & 1.4 & $0.2-6.9$ & 0.701 \\
\hline Cohabitating $(\mathrm{n}=24)$ & 3 & 12.5 & 2.7 & $0.4-13.9$ & 0.169 \\
\hline Separated $(n=36)$ & 13 & 36.1 & 10.8 & $3.4-37.8$ & $<0.001$ \\
\hline
\end{tabular}

${ }^{\wedge}$ Two participants who did not provide information on their relationship status were excluded from analysis; OR = odds ratio; CI = Confidence Interval; "Married women are the reference group against whom the other groups were compared.

IPV indicated an increased risk of intimate homicide for victimised women (however, at the time of the study none of the female participants was murdered). These factors may include experiences of threats to be killed, attempted strangulation, burning, or drowning, victimisation by an object, threats by the partner to use an object to 
hurt the woman, and threats to hurt children, which are known to be associated with an increased risk of intimate partner homicide. In this Australian context, the experiences of MP-IPV were found to differ by Aboriginal status and relationship status.

These findings corroborate existing international research suggesting that Aboriginal women are at a significantly higher risk of intimate partner homicide than non-Aboriginal women [8]. Despite the very small number of Aboriginal participants, it is noteworthy that they were found to be nearly 16 times more likely to experience potentially lethal forms of IPV than non-Aboriginal women in the six months prior to the study. Although awareness is growing that the prevalence of physical and sexual violence in intimate relationships is significantly higher among Aboriginal women than non-Aboriginal women [20], Aboriginal women continue to suffer increased disadvantage due to racist and stereotypical views towards their ethnic and cultural background [20]. Harry Blagg noted that "Aboriginal women are probably the most repeatedly and multiply victimised section of Australian society, and the main perpetrators of violence against Aboriginal women tend to be their own male kin [24]".

It has been argued that police officers at a scene may sometimes downplay the seriousness of MP-IPV [25], which is even more so when the victims are Aboriginal women because of the erroneous perceptions that violence is an Aboriginal cultural phenomenon. In order to prevent fatal outcomes of MP-IPV for Aboriginal women, policing issues require priority attention. For example, it may be argued that physical injuries and a higher incidence of intimate partner homicide are associated with Aboriginal women's resistance to victimisation because some Aboriginal women do not feel as if they can count on being protected by police. Hence, it is possible that a lack of support makes it necessary for these women to use physical resistance to violence as their only avenue of protection [24].

In this study, clear differences were found with regard to status of relationship and rates of MP-IPV. Women who were currently separated were at a much higher risk of potentially being murdered by their former intimate partner than women who were married, in cohabiting or dating relationships at the time of data collection. Particularly striking was the finding that nearly $42 \%$ of separated women reported threats to be killed in the past six months. While it can be assumed that not all murder threats will end in attempted or completed homicide, it is fair to argue, that they should be taken seriously.

Findings of this study seem to corroborate previous research in the US suggesting that separation is a "key risk factor of femicide [13]”. Along the same lines, Nicolaidis and colleagues found that homicide attempts took place in $73 \%$ of the cases "just around the time of a significant relationship change"... "the woman was trying to leave the relationship". The same study reported that separated women were also six times more likely than married women to have experienced attempts of strangulation, burning or drowning [11]. More research is required to examine the impact of relationship status on threats of, and completed homicide.

\section{Limitations}

This study was subject to a number of limitations. The non-random sample of participants in this study means it is not possible to generalise the results, and it is unknown how representative the sample was of all women subjected to MP-IPV. There is no information on the number of women who were invited to participate in the study, but declined, and the reasons why women would refuse to take part in the study is open to speculation.

Further, the extent of reporting bias could not be determined. Although anonymity was guaranteed through the use of non-written consent, some participants may have chosen socially desirable responses [26], or suffered from memory loss. Hence, distorted answers may have been obtained because "women tend to present themselves and their attitudes in ways that are pro-social and unthreatening to others [27]”.

\section{Conclusions}

The purpose of this paper was to add to current knowledge by reporting on risk factors associated with lethal violence by an intimate partner. Background variables were correlated with threats to kill and/or attempted homicide (potentially lethal acts of violence involving strangulation, burning, and/or drowning). Findings confirmed that women who demonstrated risk factors for intimate homicide were more likely to be separated and/or Aboriginal, and exposed to sexual violence. These key risk factors may alert legal professionals and victim support workers that lethal forms of violence may be impending.

Women are likely to be saved by observing predictable behaviours and recognising that they may escalate to homicide, particularly if the victims are of minority status and separated from their intimate partners. Frontline intervention policy developers and practitioners may implement protective measures for identified vulnerable women and their children based on findings of this study. Further research is needed to investigate specific risk factors, gather international data, and develop preventative measures based on empirical evidence.

\section{Acknowledgements}

The author would like to thank Associate Professor Frank Morgan (The University of Western Australia, Crime 
Research Centre) and Dr Katrina Spilbury (Curtin University, Curtin Health Research Institute) for their assistance in analysing the data, and Associate Professor Colleen Fisher (The University of Western Australia, School of Population Health), Dr Ann-Claire Larsen (Edith Cowan University, School of Law \& Justice), Dr Renate Zilkens (Curtin University, Curtin Health Research Institute) for their helpful comments in preparing this report. Furthermore, the financial support from the Western Australian Government, Edith Cowan University and the University of Western Australia is acknowledged.

\section{REFERENCES}

[1] M. Guggisberg, "Women, Violence and Comorbidity: The Struggle with Victimisation, Mental Health and Substance Use,” Lambert Academic Publishing, Saarbrücken, 2010.

[2] US Bureau of Justice Statistics, "Homicide Trends in the US: Intimate Homicide”, 2011. http://www.bjs.ojp.usdoj.gov/content/homicide/cfm

[3] J. Putt, "Domestic-Related Homicide: Keynote Papers from the 2008 International Conference on Homicide Australian Institute of Criminology Report Research and Public Policy Series 104,” 2009. http://www.aic.gov.au/en/publications/rpp104.aspx

[4] J. Mouzos, "Femicide: An Overview of Major Findings", Trends and Issues, Australian Institute of Criminology, Canberra, 1999.

http://aic.gov.au/en/publications/current\%20series/tandi/1 21-140/tandi124.aspx

[5] J. Dearden and W. Jones, "Homicide in Australia: 2006-2007 National Homicide Monitoring Program: Annual Report,” AIC Reports Monitoring Reports, Canberra, 2008.

[6] http://www.aic.gov.au/documents/F/F/B/\%7BFFB9E49F160F-43FC-B98D-6BC510DC2AFD\%7Dmr01.pdf?bcsi_ scan_2F83426B613409AB=0\&bcsi_scan_filename=\%7B FFB9E49F-160F-43FC-B98D-6BC510DC2AFD\%7Dmr 01.pdf

[7] A. Gallup-Black, “Twenty Years of Rural and Urban Trends in Family and Intimate Partner Homicide: Does Place Matter,” Homicide Studies, Vol. 9, No. 2, 2005, pp. 149173. doi: $10.1177 / 1088767904274158$

[8] S. Decker "Exploring Victim-Offender Relationships in Homicide: The Role of Individual and Event Characteristics,” Justice Quarterly, Vol. 10, No. 4, 1993, pp. 585612. doi:10.1080/07418829300092031

[9] J. Campbell, N. Glass, P. W. Sharps, K. Laughon and T. Bloom, "Intimate Partner Homicide: Review and Implications of Research and Policy," Trauma Violence Abuse, Vol. 8, No. 3, 2007, pp. 246-269. doi:10.1177/1524838007303505

[10] R. E. Dobash and R. P. Dobash, "The Murder in Britain Study: Broadening the Analysis of Men who Murder an Intimate Woman Partner,” In: J. Putt, Ed., Domestic-Related Homicide: Keynote Papers from the 2008 Interna- tional Conference on Homicide, AIC Reports Research and Public Policy Series 104, Australian Institute of Criminology, Canberra, 2009.

http://www.aic.gov.au/en/publications/rpp104.aspx

[11] L. Laing, J. Stubbs and B. Green, "Report of the Domestic Violence Homicide Advisory Panel,” 2009.

http://lawlink.nsw.gov.au/lawlink/Corporate/ll_corporate. nsf/vwFiles/251109_domestic_violence.pdf/\$file/251109 _domestic_violence.pdf

[12] C. Nicolaidis, M. A. Curry, Y. Ulrich, P. Sharps, J. McFarlane, D. Campbell, F. Gary, K. Laughon, N. Glass and J. Campbell, "Could We Have Known? A Qualitative Analysis of Data from Women Who Survived an Attempted Homicide by an Intimate Partner," Journal of General Internal Medicine, Vol. 18, No. 10, 2003, pp. 788794. doi:10.1046/j.1525-1497.2003.21202.x

[13] G. McClane, G. Strack and D. Hawley “A Review of 300 Attempted Strangulation Cases Part II: Clinical Evaluation of the Surviving Victim," Journal of Emergency Medicine, Vol. 21, No. 3, 2001, pp. 311-315. doi:10.1016/S0736-4679(01)00400-0

[14] W. de Keseredy, M. Rogness and M. Schwartz, "Separation/Divorce Sexual Assault: The Current State of Social Scientific Knowledge,” Aggression and Violent Behavior, Vol. 9, No. 6, 2004, pp. 675-691. doi:10.1016/j.avb.2003.08.004

[15] E. Echeburua, J. Fernandez-Montalvo, P. de Corral and J. J. Lopez-Goni, “Assessing Risk Markers in Intimate Partner Femicide and Severe Violence: A New Assessment Instrument," Journal of Interpersonal Violence, Vol. 24, No. 6, 2009, pp. 925-939. doi:10.1177/0886260508319370

[16] K. Cook and H. Jones, "Surviving Victimhood: The Impact of Feminist Campaigns”, In: S. Walklate, Ed., Handbook of Victims and Victimology, Willan Publishing, Portland, 2007, pp. 125-145.

[17] N. Harwin "Putting a Stop to Domestic Violence in the United Kingdom: Challenges and Opportunities," Violence against Women, Vol. 12, No. 6, 2006, pp. 556-567. doi:10.1177/1077801206289134

[18] E. D. Krause, S. Kaltman, L. A. Goodman and M. A. Dutton, "Avoidant Coping and PTSD Symptoms Related to Domestic Violence Exposure: A Longitudinal Study,” Journal of Traumatic Stress, Vol. 21, No. 1, 2008, pp. 83-90. doi:10.1002/jts.20288

[19] N. Glass, K. Laughon, J. Campbell, C. R. Block, G. Hanson and E. Taliaferro, "Violence: Recognition, Management and Prevention Non-Fatal Strangulation is an Important Risk Factor for Homicide of Women,” Journal of Emergency Medicine, Vol. 35, No. 3, 2008, pp. 329-335. doi:10.1016/j.jemermed.2007.02.065

[20] J. Stubbs and J. R. Tolmie, "Battered Women Charged With Homicide: Advancing the Interests of Indigenous Women," Australian and New Zealand Journal of Criminology, Vol. 41, No. 1, 2008, pp. 138-161. doi:10.1375/acri.41.1.138

[21] A. Morgan and H. Chadwick "Key Issues in Domestic Violence,” Research in Practice, Summary Paper No. 7, Australian Institute of Criminology, Canberra, 2009. 
[22] http://www.aic.gov.au/documents/5/6/E/\%7B56E09295AF88-4998-A083-B7CCD925B540\%7Drip07_001.pdf

[23] M. Guggisberg, "Relationship Problems: How Abuse in Intimate Relationships Affects Men, Women and their Children,” Cross Network Journal, Vol. 1, No. 3, 2006, pp. 128-141.

[24] C. Block, "Reducing Intimate Partner Homicide Rates: What are the Risk Factors for Death When a Woman Is Being Abused,” In: J. Putt, Ed., Domestic-Related Homicide: Keynote Papers from the 2008 International Conference on Homicide, AIC Reports Research and Public Policy Series 104, Australian Institute of Criminology, Canberra, 2009.

http://www.aic.gov.au/en/publications/rpp104.aspx

\section{APPENDIX}

\section{VAI: VIOLENCE ASSESSMENT INDEX}

Thinking of ALL the incidents that may have happened in the last six months, please indicate how many times your partner has done any of the following to you?

$0=$ Never $; 1=$ Once only; $2=2$ to 4 times; $3=5$ or more times

A Restrained me from moving or leaving the room

B Choked me or held his hand over my mouth

C Punched me in the face

D Slapped me on the face, body, arms or legs

E Pushed, grabbed or shoved me
[25] R. E. Dobash, R. P. Dobash, K. Cavanagh and R. Lewis, “Changing Violent Men,” Sage, London, 2000.

[26] H. Blagg, "Restorative Justice and Aboriginal Family Violence: Opening a Space For Healing,” In: H. Strang and J. Braithwaite, Eds., Restorative Justice and Family Violence, Cambridge University Press, Cambridge, 2002, pp. 191-205.

[27] A.-C. Larsen and M. Guggisberg, "Police Officers, Women and Interpersonal Violence: Giving Primacy to Social Context," Australian Journal of Gender and Law, Vol. 1, 2009, pp. 1-18.
F Punched me on the body, arms or legs

G Used an object to hurt me

$\mathrm{H}$ Threw things at me or about the room

I Punched or kicked the walls or furniture

$\mathrm{J}$ Tried to strangle, burn or drown me

$\mathrm{K} \quad$ Kicked me on the body, arms or legs

L Threatened me with an object or weapon

$\mathrm{M}$ Kicked me in the face

$\mathrm{N}$ Threatened to kill me

O Twisted my arm

$\mathrm{P} \quad$ Dragged me or pulled me by my hair

Other violent behaviours not mentioned above 